\title{
Urban firefighting: Qualitative exploration of occupational challenges faced by firefighters of Kathmandu valley, Nepal
}

\author{
Bhattarai S1, KC P1', Gyawali A1, Lamichhane A1', Giri A', Kakchapati $\mathbf{S}^{2,3}$ \\ ${ }^{1}$ Masters of Public Health Candidate, Department of Public Health, Nobel College, Pokhara University, \\ Kathmandu, ${ }^{2}$ Research Coordinator, Department of Public Health, Nobel College, Pokhara University, ${ }^{3}$ Director, \\ Research and Evaluation, Integral Research Center, Nepal, Kathmandu
}

\section{ABSTRACT}

Introduction: Urban firefighting is a challenge however very less is known about how the firefighters manage on addressing fire disasters when it occurs or what sort of health risks they generally face. The health risks in firefighting are abundant however very less is explored, in regard to the Nepalese context. This study thus aims to explore general characteristics and potential stress causing factors among urban firefighters of Kathmandu valley as Nepal lacks any such study.

Methods: A qualitative study design with in-depth interview questions were used to interview 15 currently employed firefighters and the station in charge of Kathmandu valley and thematic analysis was done to derive results. The study was conducted in two phases, the first phase including the use of locally translated and validated DASS-21 (Depression Anxiety and Depression Scale) tool to identify potentially stress suffering firefighters while the second phase included use of in-depth interview (IDI) and key informant interview (KII) format to explore stress causing factors among firefighters.

Results: The results showed that most firefighters were stressed due family separations, difficult PPEs, lack of human resource adequacies, income insufficiency, underwhelming response at active site and lack of health addressing programs in the station. The firefighters additionally mentioned stress due to recurring bluff calls and unmanaged traffic in the city.

Conclusion: Despite the solvable problems, the station lacked standard operating guidelines, physical fitness and mental well-being programs, deemed essential for the occupation in general. Therefore, concerned authorities must prioritize the needs of urban fire station and firefighters to timely respond increasing fire accident risks and establish occupational well-being among firefighters.

Key words: Nepalese Fire Station, Operating Process, Stress, Urban Firefighters.

\section{Introduction}

$\mathrm{N}$ epal has been known to have proportionately higher number of natural disasters, especially fire

DOI: https://doi.org/10.3126/ijosh.v11i2.35982

Conflicts of interest: None

Supporting agencies: None

Date of submission: 24.03.2021

Date of acceptance: 03.06.2021

Date of publication: 20.06.2021

\section{Corresponding Author}

Shivani Bhattarai

Master of Public Health Candidate,

Department of Public Health,

Nobel College, Pokhara University,

Sinamangal, Kathmandu, 44601

E-mail: shivani.bhattarai@yahoo.com

Mobile no.: 977-9841547541; Telephone no.: 014912736

ORCID ID: https://orcid.org/0000-0002-4512-4547 mishaps over the years. Review of the disasters from 1971-2018 reveals that fire comes as the top most form of disaster with 12694 number of incidents and 1755 cost of lives in Nepal. ${ }^{1}$ Just in between 2017 and 2018 , fire incidents had cost the country with highest economic damage, killing 150 and further injuring 557 people. ${ }^{2}$ Around five percent people facing these fire incidents suffer severe disabilities which is also the second highest cause of injuries in Nepal. ${ }^{1}$ These fire incidents are expected to further increase due to poorly developed urban settlements, densely populated areas, reinforced by increased use of plastic products and human negligence. ${ }^{2,3}$

\section{(c) (1) (9)}

This journal is licensed under a Creative Commons AttributionNon Commercial 4.0 International License. 
As the unplanned urbanized settings are highly exposed to occurrences of fire incidents, the habitants and settlements of Kathmandu valley which is highly unorganized, poses an increased mortality and morbidity risks alongside huge economic damages. ${ }^{4}$ Nepal deems to have strong political commitments to address the disasters, however only $11 \%$ local government currently have a disaster risk management plan with poorer proportion of concerned authorities aware of natural disaster management strategies if and when it occurs. ${ }^{2,5}$ Although fire is most frequent and economically damaging disaster, fire response and preparedness especially in Kathmandu valley seems to be highly compromised. Excluding the army and aviation authorities' stations, only two functional fire stations are currently responding the fire disasters in the valley. However, the fire stations merely have standard station management practices, adequate firefighting equipment and operational problems associated with the frontline urban firefighters. ${ }^{6}$ Firefighting station and fire disaster response system being under addressed, firefighters who are directly exposed to the incident sites are expected to face numerous health risks. As firefighting is known to be the worlds' riskiest jobs, lack of standard institutional and occupational environment does expose not only the firefighters but also the victims trapped in fire to face life threatening situations. ${ }^{7}$

With frequent and continuous fire exposures, health outcomes such as cardiovascular diseases, hearing problems, respiratory problems, musculoskeletal disorders and injuries are common among professional firefighters. $^{8} \quad$ Firefighters additionally face work associated stress, family and work conflicts and higher frustration levels due to their occupational requirements inducing mental health problems. ${ }^{9,10,11,12}$ The studies done across firefighting sector indicate the need of critically developed safer working structures and conducts to fit into this risky profession ${ }^{13}$, however there is limited evidence in Nepal that explores the condition of Nepalese fire stations or the firefighters. Since many lives are dependent on these emergency responders, their issues must be explored to lobby for safer rescue operations as well as assuring minimal occupational health hazards for these firefighters. This exploratory study therefore intends to identify any work associated psychological stress among urban firefighters of Kathmandu valley and the existing situation of the fire stations that may be potentially contributing to their stress reasoning. The study could potentially contribute as an evidence for responsible local authorities in developing a better work environment for these firefighters by acknowledging the existing challenges they face on-duty. The study uses critically developed data collection tools to explore these factors in an in-depth manner and therefore contribute to the existing purpose of this study.

\section{Methods}

The objective of this study was to explore the current occupational challenges among the urban firefighters of Kathmandu valley. Therefore, Juddha Fire Station located at Basantapur, Kathmandu, one of the two fire stations within Kathmandu valley was purposively selected as the study setting. This specific fire station staffed with around 32 employees is the first and oldest fire station of Nepal, occasionally seeking support from Nepal Army and Civil Aviation's firefighting team while addressing high risk incidents. Officially recruited firefighters who already had field firefighting experiences were selected as the study participants. The data collection was done in two steps, first consisting of the use of locally translated and formerly validated DASS-21 (Depression, Anxiety, and Stress Scale) measurement tool to identify firefighters who face some levels of occupational stress among the recruited firefighters in the station on the day of data collection. Fourteen out of eighteen firefighters present in the station showed mild-moderate stress post DASS21 screening. These 14 firefighters and one station in charge were interviewed in local language via qualitative in-depth interviews using in-depth interview (IDI) tools and key informant interview (KII) guideline developed on the basis of available literatures for the study. All the interviews were audio recorded with mobile devices and handwritten notes, later transcribed into electronic notes by the interviewers themselves. The qualitative analysis was performed manually on the transcriptions starting by the development of initial codes which were further categorized among ten suitable subthemes and three major themes. Ethical clearance was taken from the Institutional Review Committee (IRC) of Nobel College for conducting the study. All the participants provided written consent for their participation while their identities have been redacted for ethical purposes.

\section{Results}

The results for the study were developed from familiarization of details shared by the participants. From the use of DASS-21 tool that identified 14 out of 18 firefighters to be mild and moderately depressed, and these 14 firefighters in addition to 1 station in charge were approached for qualitative interviews in the second phase. Post the interviews, appropriate 
codes for the responses were developed, and upon manual analysis, these were developed into suitable subthemes. Based on the similarity of the responses, appropriate themes were then developed for ascending the study results. The results have been presented in 3 themes namely characteristics of the firefighters, characteristics of the fire station and problems faced by firefighters, further disaggregated into 10 subthemes accordingly.

\section{Characteristics of the firefighters}

\subsection{Socio-demographic Characteristics}

Table 1: Socio-demographic characteristics of the participants

\begin{tabular}{|c|c|c|c|}
\hline Characteristics & \multicolumn{3}{|c|}{ Frequency } \\
\hline \multirow{2}{*}{ Age } & $<25$ & $\geq 2$ & \\
\hline & 3 & 15 & \\
\hline \multirow{2}{*}{ Gender } & Female & Mal & \\
\hline & 0 & 18 & \\
\hline Ethnicity & $\begin{array}{c}\text { Brahmin/ } \\
\text { Chhetri } \\
10\end{array}$ & $\begin{array}{r}\text { Newar and } \\
8\end{array}$ & Janajati \\
\hline Marital status & $\begin{array}{c}\text { Married } \\
12\end{array}$ & $\begin{array}{c}\text { Unmar } \\
6\end{array}$ & ried \\
\hline \multirow[t]{2}{*}{ Education } & $\begin{array}{l}\text { No } \\
\text { response }\end{array}$ & $\begin{array}{c}\text { SLC to } \\
\text { Intermediate }\end{array}$ & $\begin{array}{c}\text { Graduate } \\
\text { and } \\
\text { above }\end{array}$ \\
\hline & 3 & 11 & 4 \\
\hline $\begin{array}{c}\text { Average } \\
\text { monthly income }\end{array}$ & $\begin{array}{c}<\text { NRs } . \\
25000 \\
7\end{array}$ & \multicolumn{2}{|c|}{$\geq$ NRs. 25000} \\
\hline
\end{tabular}

The firefighters recruited were mostly referred from the Armed Police Force (APF) department based on their skills and positional requirement of the fire station. Fifteen of the study participants were 25 years and above while only three were below 25. All the firefighters were male, with 10 belonging to Brahmin/ Chhetri ethnicity and remaining 8 were Newar and Janajati. Twelve participants were married and other six were unmarried until the day of the interview. Only four participants had an education level of graduate and above, 11 had completed school leaving certificate (SLC) or intermediate level while three chose not to respond. Out of 18 participants, 11 participants shared that their salary was NRs. 25000 and above while remaining seven had below NRs. 25000. In addition, 13 firefighters expressed that they were living separately from them family due to their job shift requirements.
A total of fourteen firefighters and one senior official (station in-charge) were selected and interviewed for the study. The age ranged between 22 to 50 years whilst the minimum age of joining firefighting was 20 years. Majority of the firefighters came through Nepal Armed Police Force (APF) referrals. All firefighters were literate and had cleared at least SLC (School Leaving Certificate) before engaging as a firefighter. Given their 24 hour job shifts, most interviewed firefighters were separated from their families which were expressed as stressful at times for the firefighters.

"We have emergency duties and so we spend most of the time in the station. My wife looks after our children and I get to visit them during vacations. I think of them at times, and sometimes it's difficult staying apart from them." (IDI 7)

\subsection{Firefighter placement process, job descriptions and capacity development}

The firefighters being primarily referred from APF followed the recruitment criteria of police force, which needed them to be aged between 18-25 years, body weight above 50 kilograms, physically fit and had to clear metropolis based examination for being shortlisted. After being recruited as police officer, based on the human resource requirement of the fire stations, they are shifted to fire stations as firefighters. Many of them knew that their job was 24 hour-shift in the station but neither were provided with standard job descriptions as none were aware if the station even had any operating guidelines or any standard recruitment practices other than just referrals.

These days, people aren't much interested in firefighting. I don't think there is any criteria for being a firefighter as I was referred from police service, but must should have such." (IDI 11)

The station in-charge unhappily further added:

"There is no such law/guideline to hire! It has become so many years but still we are hired through APF referrals." (KII)

The firefighters were provided with orientation, drills, simulations and trainings for the job through the station after recruitments. However, few firefighters shared that the current trainings weren't sufficient for their capacity building to tackle fire incidents and that increased training frequencies with special sessions on equipment maintenance and handling must be in place. 
"We get trainings after we join station, but it isn't enough, we need more improved and regular training to refresh our learnings." (IDI 7)

\section{Characteristics of the fire station}

\subsection{Frequency and types of calls}

Around 50 bogus calls a day would be generally made in the fire station, which stressed few firefighters, to the instance that they would feel irritated by their own phone calls. However, many of them developed resilience after few years' tenancy.

"I was much stressed about the station calls that came back to back, even when the telephone at my own home rang, I would feel anxious." (IDI 1)

Since majority of calls were pretense, it would generally be harder for firefighters to identify which of the calls made real accident reports. Only after double assuring with local police, traffic or volunteers, the firefighters would leave for the rescue mission, which lengthened their overall response time. Additionally, the person reporting fire accident cases mostly seemed to exaggerate the real scenario, which would build pressure and stress on firefighters until they reached the site for response.

"Sometimes they elaborate their descriptions and we have to be back from middle way. It stresses us a bit but we are used to it as well now." (IDI 3)

\subsection{Standard rescue procedure and program operating guidelines}

The station didn't provide any evidence of operation manuals or valid guidelines to follow for rescue missions or stations' operation. Firefighters followed weekly roosters to perform their duties while none seemed to be bothered by the fact that there were not any organizational norms, guidelines or documents which should have illustrated their roles, responsibilities, occupational benefits or compensations required as such risky line of work.

"We work in such a field that no such policy is required; we all can work well because we know where the goods and how to manage it well." (IDI 1)

The station in-charge expressed being bothered as no operational guidelines could have been made despite his efforts over the years. With the absence of operational guidelines, the recruitment processes, budgeting and training programs and appraisal systems have been highly affected as they lack autonomy in its absence. The guideline and policies that could have safeguard the rights and direct additional incentives to firefighters also could not be executed as a result.

"Despite the complimentary changes in different sectors of Nepal such as in construction and agriculture, almost no focus has been given to fire disaster response in Nepal." (KII)

\subsection{Disaster response process}

Generally, a team of eight firefighters would lead a fire response mission. However, few firefighters believed that the number of members in the team aren't sufficient for general fire accident site and they occasionally were stressed out by this practice.

"The human resources are not enough and when such happens, we are continuously stressed until the fire is properly managed." (IDI12)

\subsection{Incentives and rewards}

There is no rule for rewards or punishments in the station which constantly probes questions such as "When do we reward the firefighters?" and "Which action is punishable", which are mostly unanswered. The station in-charge seemed bothered that good work could not be appreciated in the absence of such policy. However, firefighters were covered with accidental insurance schemes but most being unaware that they are even being covered.

"I don't know about the rewards even if we work hard. I have heard that we get some kind of insurance, but I don't know exactly what." (IDI 11)

\subsection{Fitness and health programs}

The fire station lacked physical fitness area or any provision encouraging firefighters to perform duty-fit workouts. Firefighters did basic stretches and morning runs for their physical finesses. Almost all firefighters emphasized the need of well-equipped gym or fitness area to keep their physical strength in check as they need their strength for work.

"We do not have anything for physical exercise. I exercise as we did during our APF trainings and play badminton game for self-refreshment. I feel that there must be a fitness area for us." (IDI 9)

Additionally, there is no provision of regular or periodic health screenings services, while they seek medical attention on their own if they felt unwell. Since the firefighters also repeatedly face destructive sights on their fields, most of them feel stressed by such 
sightings, some even losing sleep after field duties. However, the station lacked any stress management or coping programs but frequently organized de-briefing sessions. Playing common games with friends, such as carrom board would relieve stress of few of them. All the firefighters believed that a stress management program is essential as they face repeated traumas during their active fields.

"There isn't any provision of stress management activity in the office. We share with each other about our feelings, but I really think a separate program is necessary for us." (IDI 13)

\section{Problems/Experiences faced by firefighters}

\subsection{Working conditions during response operations}

Firefighters have been using individually allotted older models of Personal Protective Equipment (PPE) which are general heavy however the regular use makes firefighters habitual to its weight. Firefighters expressed that the heaviness of PPE and having to carry heavy water pipes, furniture during salvage process, ladders and breathing apparatuses would frequently stress them during their response operations.

"Normally, PPEs are not that heavy as compared to other equipment like ladders, foams, pipes, ropes which are usually heavy and we need to carry all those into tall building along with the victims. They weight around 30-40 kilograms, which makes our work even more challenging." (IDI7)

Firefighters also added that they are exposed to fumes for several hours irrespective of PPEs they wear. Majority of them faced health difficulties such as shortness of breath, coughing black sputum and burning sensations in their eyes, which stressed them at some level.

"I feel difficulties by gaseous exposure as it obviously affects our health, however we compromise and work." (IDI 3)

\subsection{Income insufficiency}

Although firefighters face family-separation and a 24hour station-shift based duty, they are paid according to the government norm, along with $33 \%$ risk incentive. Most firefighters believed that their income was insufficient compared to their occupational risk.

"We get paid but there are so many risks we have to face on an active fire scene. With all the protective equipment we wear, we get tired. I think we must be compensated well enough!" (IDI 2)

\subsection{Mental and emotional distress in firefighters}

Family separations, physical exertion, an immoral public response, uncomfortable PPEs, sighting fatalities, gaseous exposures and income insufficiency are causing stress among firefighters. The unmanaged traffic despite sirens, depraved road conditions, narrow trails and substandard houses affect their arrival upon which people react rashly, making them demotivated and even wanting to leave the site hurriedly.

"I get bad temper when I go to the road. People yell at us without any reason and even throw stones at us saying we came after the fire was extinguished. I feel annoyed when this happens!" (IDI 9)

The emergency service readiness has been affecting station in-charge differently and at all times.

"Until I am in the station compound, all of my attention is on my radio set. I continuously think of only receiving fire disaster notifications and once I leave the station, I have my full attention to my mobile set for the same reason!" (KII)

\section{Discussion}

This study so far known is the first qualitative study to explore the problems faced by urban firefighters of Nepal. All the firefighters are recruited through APF standards and referrals with minimum education qualification required for the job. The firefighters have 24 hour job shift, because of which they are mostly separated from their families. The firefighters were aware of their responsibilities however the norms of standard job practices seemed missing due to lack of station operating guideline and station management policies. Most firefighters expressed the need of better training strategies, health related services, increment in monthly income and better firefighting equipment for improving their firefighting experiences.

The currently recruited firefighters in the station, do have a nominal age however as few firefighters are below 25 years and majority are above 25 years. The lesser aged firefighters do bear lesser workassociated stress ${ }^{14}$ but are also known to be lesser productive who lack decision making capabilities and cognitive performance during emergency situations. ${ }^{15}$ With increased age and increased experiences of job distress that only grows with age factor, these young firefighters have higher risk of developing perceived 
mental strain (PMS) in the long run. ${ }^{15}$ In addition, the lack of any higher level education in firefighter limit their capacity to understand the training and equipment user manuals ${ }^{14}$ probing job-stress and lack of understanding regarding stress coping methods. ${ }^{16}$ It is therefore imperative that these firefighters have proper educational foundations and are familiar with resilience developing programs for coping these stress causing factors due to their occupational requirements. ${ }^{17}$

The 24 hour job shift that engage them are further known to cause family-related conflicts, emotional exhaustion, stress and even family separations if the conflicts go unresolved. ${ }^{18}$ The lack of standardization regarding both age and education is somehow enabled by the lack of standard recruitment processes and established job descriptions for firefighters. These management gaps lead to inappropriate firefighters' evaluation and sanctions ${ }^{18}$ while neglecting the rights to information to firefighters and violating transparency practices in the station. ${ }^{19}$

Firefighting is already a stressful and risky occupation topped with recurring useless calls sparks irritation and lack of job interest amongst firefighters..$^{20}$ The human resource inadequacies often felt by the firefighters overstresses firefighters and affects team work, increasing the long term risk of both physical and mental exertions among firefighters. ${ }^{14}$ In addition, the heavy traffic of the busy roads of Kathmandu hinders these firefighters and fire brigade to reach the accident destination on time. As a result, people face higher damages, with possibilities of life loss ${ }^{21}$ which not only stresses them but the unwelcoming behavior of the public upon delayed arrival deteriorates the confidence of firefighters. The psychological well-being of the firefighters is thus challenging.

Firefighters mostly were dissatisfied with the amount of incentives provided for their laborious work. In the absence of rewards and punishment criteria which are generally depicted in the organizational/institutional charters and guidelines, they are bound to get the minimum wage established as per the government norms. This dissatisfaction prolonged may demotivate firefighters and affect their job performances. ${ }^{22}$ On the other hand, this absence of standard operating procedures, the station has also foundered to entitle standard roles for recruited firefighters increasing the possibilities of duty conflicts, longer assignments, increased work exposure and longer family separation. ${ }^{23}$ The standard operating guidelines (SOP) and workplace policy are thus substantial to determine a proper course of action leading to healthy workplaces, value employees, promote work performances and maintain harmony among existing employees. ${ }^{24}$

The study has illustrated that these urban firefighters have multiple stress causing factors associated with their occupation. But the other major attribute required to firefight is the physical fitness as they must lift heavy equipment and salvages along with the weight of their own PPEs. Firefighters not only face mobility challenges due to heavier PPEs ${ }^{23}$ but also suffer from musculoskeletal disorders along with the breathing problems due to prolonged gaseous exposures ${ }^{9}$. They require both easy to carry PPEs and routines to keep themselves physically fit. However, the firefighters or the fire station lacking fitness rooms implies compromised fitness preferences ${ }^{26}$ challenging their capabilities to address critical incidents. ${ }^{17}$ The station thus needs to focus on developing physical fitness strategies for increasing the firefighter's efficiency to address disasters. On the contrary, firefighters do engage in debriefing sessions which does relieve some levels of stress however it solely does not ensure their psychological well-being due to their frequent exposures to dreadful fire incidents and victims. ${ }^{27,28}$ The fire station thus must be able to address the health needs of the firefighters by means of health promotion interventions addressing both their physical and psychological needs to assure their well-being. ${ }^{29}$

As there have not been any previous studies regarding the stress causing factors among urban Nepalese firefighters, this study explores these factors with expectations that it may call attention to concerned stakeholders with intentions to resolve the identified problems. However, the study had some limitations. The findings are exploratory in nature based on small sample size which may present different views from other similar studies while a quantitative study is required to generate better evidence to explore the facts better. In addition, inclusion of only those respondents willing to participate may imply that participants were mature, and their answers may have been positively biased. Also, the mix of mature and newly recruited firefighters in this study may vary the real work associated experiences in this field. ${ }^{30}$

\section{Conclusion}

The urban population of Kathmandu valley are at higher risk of facing fire disasters while there are limited 
resources or stations to do so. The Juddha fire station, oldest of the fire stations is serving millions of those in Kathmandu valley however the station lacks standard operating guidelines to conduct its operations. The station operates through its own culture, developed as standard practices and daily routine developments. With lack of standard operating system and documental bases, the recruitment and skill development process are poor while lack of appropriate occupational benefit packages also affect firefighters psychologically. Additionally, firefighting relies heavily on physical capacities, however no physical fitness programs was present in the station. The major source of occupational dissatisfaction were thus income, lack of physical fitness and psychological support program among the firefighters under study. Occupation associated physical exertion, PPE heaviness, gaseous exposures, delay in response due to heavy traffic and poor public response were major cause of stress among firefighters however no programs or activities addressed their problems so far, which increases physical and mental health risks among firefighters. The local government and disaster management divisions must be aware of the situation and react in best possible ways as to address needs of firefighters, fire station with standard operation processes so that appropriate response and preparedness to fire disaster in such urban areas can be developed.

\section{References}

1. Nepal Disaster Management Reference Handbook. Center for Excellence in Disaster Management \& Humanitarian Assistance. October 2020. Available from: https://reliefweb.int/sites/reliefweb.int/files/ resources/disaster-mgmt-ref-hdbk-nepal-2020. pdTwigg J, Christine N, Haworth J, Osuteye E, Skarlatidou A. Improved methods for fire risk assessment in low-income and informal settlements. International Journal of Environmental Research and Public Health. 2017;14:139.

2. Ministry of Home Affairs (MoHA). Nepal Disaster Report 2019. Ministry of Home Affairs, Government of Nepal. 2019. Available from: http://drrportal.gov.np/ uploads/document/1594.pdf

3. Masoumi Z, Genderen JVL, Maleki J. Fire Risk Assessment in Dense Urban Areas Using Information Fusion Techniques. International Journal of Geolnformation. 2019;8:579.

4. Thapa RB, Murayama Y, Ale S. City profile: Kathmandu. Cities. 2008;25:45-57.

\section{Acknowledgements}

The authors acknowledge the inputs to the station in-charge of Juddha Fire Station, Mr. Lilaraj Gaccha Thapa Magar, for contributing his time and essential information for this study.

\section{Authors' contributions}

SK conceived the study concept. SB conducted literature searches, developed the research tools and all authors contributed towards data collection, transcription and coding. SB performed analysis and wrote the manuscript. All authors contributed in the finalization of the manuscript.

\section{What we already know:}

Kathmandu, Nepal has poorly developed urban structures which developed the risk of fire accidents increasing occupational burden among urban firefighters however the fire response system in the valley is poorly developed, which mostly may be affecting firefighters' health and wellbeing.

\section{What this article adds:}

What are the occupational factors affecting urban firefighters and what kind of risks they may be facing in the future if concerned authorities still disregard station's needs and addressing occupational health determinants of urban firefighters of Kathmandu valley.

5. Malla SB, Dahal RK, Hasegawa S. Analyzing the disaster response competency of the local government official and the elected representative in Nepal. Geoenvironmental Disasters 7, 15 (2020). https://doi.org/10.1186/s40677-020-00153-z2020;15.

6. Hardison CM, Lim N, Keller KM, Marquis JP, Payne LA, Bozick R, et. al. Recommendations for Improving the Recruiting and Hiring of Los Angeles Firefighters. RAND Corporations, Santa Monica, California. 2015; ISBN: 978-0-8330-8839-0. Available from: https:// www.rand.org/content/dam/rand/pubs/research reports/RR600/RR687/RAND_RR687.pdf

7. Shokouhi M, Nasiriani K, Khanken H, Fallahzadeh $H$, Zavareh DK. Exploring barriers and challenges in protecting residential fire-related injuries: a qualitative study. J Inj Violence Res. 2019;11(1):81-92.

8. Graveling RA, Crawford JO. Non-cancer occupational health risks in firefighters. Occupational Medicine. 2012;62(7):485-95.

9. Kim MG, Kim KS, Ryoo JH, Yoo SW. Relationship between Occupational Stress and Work-related Musculoskeletal Disorders in Korean Male Firefighters. 
Annals of Occupational and Environmental Medicine. 2013;25(1):9.

10. Smith TD, Hughes K, DeJoy DM, Dyal MA. Assessment of relationships between work stress, work-family conflict, burnout and firefighter safety behavior outcomes. Safety Science. 2018;103:28792.

11. Rouse PC, Turner PJ, Siddall AG, Schmid J, Standage M, Bilzon JLJ. The interplay between psychological need satisfaction and psychological need frustration within a work context: A variable and person-oriented approach. Motivation and Emotion. 2020;44: 175-89.

12. Cook B, Mitchell W. Occupational health effects for firefighters: The extent and implications of physical and psychological injuries (Report prepared for the United Firefighters Union of Australian Victorian Branch). Centre of Full Employment and Equity. 2013. Available from: https://www.aph.gov.au/ DocumentStore ashx?id=6b768cf1-2ead-450a-8037f03a53e8d $7 \mathrm{~b} 2 \&$ subld $=613112$

13. Lusa S, Punakallio A, Luukkonen R, Louhevaara V. Factors associated with changes in perceived strain at work among fire-fighters: a 3-year followup study. International Archives of Occupational and Environmental Health. 2006;79:419-26.

14. Occupational Safety and Health Administration, U.S. Department of Labor. Fire Service Features of Buildings and Fire Protection Systems. 2015. Available from: https://www.osha.gov/sites/default/ files/publications/OSHA3256.pdf

15. Fain P. Advanced Degrees for Fire Chiefs. Inside Higher Ed. 2011. Available from: https://www. insidehighered.com/news/2011/10/27/collegedegrees-increasingly-help-firefighters-get-ahead

16. Blaney L, Brunsden V. Resilience and health promotion in high-risk professions: A pilot study of firefighters in Canada and the United Kingdom. International Journal of Interdisciplinary Organizational Studies. 2015;10: 23-32.

17. Saijo Y, Ueno T, Hashimoto Y. Twenty-Four-Hour Shift Work, Depressive Symptoms, and Job Dissatisfaction Among Japanese Firefighters. American Journal of Industrial Medicine. 2008;51(5): 380-391 [DOI: 10.1002/ajim.20571]

18. Hardison CM, Lim N, Keller KM, Marquis JP, Leslie AP, Bizick R, et. al. Recommendations for Improving the Recruiting and Hiring of Los Angeles Firefighters. RAND Corporation. 2015. ISBN: 978-0-8330-8839-0.

19. Adhikari, E. Understanding Nuances and Commonalities of Job Descriptions. Journal of Training and Development, Vol. 1, July 2015, pp. 6776, doi:10.3126/jtd.v1i0.13093.

20. Duran F, Woodhamd J, Bishopp D. An Interview Study of the Experiences of Firefighters in regard to Psychological Contract and Stressors. Employee Responsibilities and Rights Journal. 2018;30:203-26.

21. Challands N. The relationships Between Fire Service Response Time and Fire Outcomes. Fire Technology. 2010;46(3):665-76.

22. Nishishiba M. Portland Fire and Rescue Workplace Culture Assessment. Portland State Centre for Public Service. 2014. Available from: https://www. portlandoregon.gov/fire/article/711079

23. Brooks SK, Dunn R, Amlot R, Greenberg N, Rubin GJ. Social and occupational factors associated with psychological distress and disorder among disaster responders: A systematic review, BMC Psychology. 2016;4:18.

24. Booysen $L$. The development of inclusive leadership practice and processes. In B. Ferdmand \& B. Deane (ed.), Diversity at Work: The practice of Inclusion. 2014;296-39.

25. Son SY, Lee JY, Tochihara Y. Occupational Stress and Strain in Relation to Personal Protective Equipment of Japanese Firefighters Assessed by a Questionnaire. Industrial Health. 2013;51(2): 214-22.

26. MarkAG, Katie S, Katie D. Design and Implementation of Fitness Programs for Firefighters. Strength and Conditional Journal. 2011;33(4):31-42.

27. Harris MB, Baloglu M, Stacks JR. Mental health of trauma-exposed firefighters and Critical Incident Stress Debriefing. Journal of Loss \& Trauma. 2011;7(3): 223-38.

28. Jahnke SA, Postin WSC, Haddock CK, Beth M. Firefighting and mental health: Experiences of repeated exposure to trauma. IOS Press content Library. 2016;53(4): 737-44.

29. Carrico, CP. Look inside firefighter families: a qualitative study. Dissertations. University of Northern Colorado. 2012. Available from: https://core.ac.uk/ download/pdf/217307586.pdf 